REVIEW ARTICLE

\title{
Disparities in germline testing among racial minorities with
} prostate cancer

\author{
Nicole Weise ${ }^{1}$, Justin Shaya ${ }^{1}$, Juan Javier-Desloges ${ }^{1}$, Heather H. Cheng $\mathbb{D}^{2,3}$, Lisa Madlensky ${ }^{1}$ and Rana R. McKay (D ${ }^{1 凶}$ \\ (c) The Author(s), under exclusive licence to Springer Nature Limited 2021
}

Germline testing is becoming increasingly relevant in prostate cancer (PCa) screening, prognosis, and management. A subset of patients with PCa harbor pathogenic/likely pathogenic variants (P/LPVs) in genes mediating DNA-repair processes, and these P/ LPVs have implications for cancer screening, treatment, and cascade testing. As a result, it is recommended that all men with highrisk localized and metastatic PCa undergo routine germline testing. As more PCa patients undergo germline testing, it is important that clinicians and genetics experts recognize current disparities in germline testing rates among racial/ethnic minorities in the United States. The reasons for these disparities are multiple and require similarly manifold consideration to close the germline testing gap and reduce inequities in PCa screening, management, and treatment.

Prostate Cancer and Prostatic Diseases (2022) 25:403-410; https://doi.org/10.1038/s41391-021-00469-3

\section{INTRODUCTION}

Prostate cancer ( $\mathrm{PCa}$ ) is the most common cancer among men and one of the leading causes of deaths worldwide [1]. In 2021, it is estimated that 248,530 men in the United States (US) will be diagnosed with PCa and 34,130 individuals will die secondary to this disease [2]. While age, race/ethnicity, and family history are established risk factors for $\mathrm{PCa}$, it is now recognized that a proportion of PCa susceptibility is attributed to genetic predisposition. Advances in molecular sequencing technologies have identified several PCa susceptibility genes, many related to known hereditary cancer syndromes, including hereditary breast and ovarian cancer (HBOC) syndrome (BRCA1, BRCA2, ATM, CHEK2, and PALB2) and Lynch syndrome (MLH1, MSH2, MSH6, and PMS2) [3]. As a result of these findings, recommendations for germline testing based on clinical features and family history have expanded. The identification of pathogenic/likely pathogenic variants (P/LPVs) in PCa predisposition genes may help inform cancer screening strategies for patients and family members, treatment options in the metastatic setting, and clinical trial enrollment.

As germline testing becomes more clinically relevant and widely available, it is important to recognize the risk of exacerbating health disparities among racial/ethnic minorities with PCa and develop systematic strategies to bridge disparities in germline testing. Reasons for these disparities are multifaceted and include patient, clinician, and system factors. Additionally, current PCa clinical trials and genetic studies do not reflect the diverse populations of individuals at-risk or suffering from this disease. In this review, we discuss the indications for germline testing in men with PCa, barriers to germline testing in diverse populations, and potential strategies to bridge the disparities gap with the expansion of germline testing for men with PCa.

\section{DISPARITIES IN OUTCOMES OF MEN WITH PCA}

There are documented disparities in the incidence, treatment, and mortality of PCa between Black and non-Black men $[2,4-6]$. Notably, Black men are diagnosed with PCa at nearly twice the rate of non-Hispanic white (NHW) men [2], and Black men with local/regional PCa have been found to be less likely to receive treatment with curative intent than NHW men [7]. Further, the PCa mortality rate is twice as high in Black men compared to NHW men [2]. The National Cancer Institute estimates that Black men have a $4.72 \%$ lifetime risk of dying of PCa compared to a $2.86 \%$ risk among NHW men [5]. Although biological differences may account for a portion of the disparity in overall PCa survival, it has been suggested that improved access to care, including screening, follow-up, and therapy may be effective in reducing this disparity [8]. It is important to note that one limitation of studies of PCa incidence and mortality is that most data on Black men does not stratify them by country/region of origin-Black men are not a homogenous group and there may be differences in $\mathrm{PCa}$ incidence and mortality for Caribbean, African, and AfricanAmerican men [9].

Similarly, despite the genetic and cultural diversity of Hispanic men in the US, individual subgroups are typically combined. Notably, significant heterogeneity has been observed among Hispanic men with PCa [10]. Overall, PCa occurs less often in Hispanic men than in NHW men [1]. However, Mexican-American men have been found to have more advanced stage PCa at diagnosis [11] and are significantly more likely to have aggressive PCa following radical prostatectomy [12]. While prostate cancerspecific mortality (PCSM) is comparable between Hispanic and NHW men, Puerto Rican men have been shown to have significantly higher PCSM than NHW men, Black men, and all

\footnotetext{
${ }^{1}$ University of California San Diego, San Diego, CA, USA. ${ }^{2}$ University of Washington, Seattle, WA, USA. ${ }^{3}$ Fred Hutchinson Cancer Research Center, Seattle, WA, USA. email: rmckay@ucsd.edu
} 
Table 1. Representation of diverse racial/ethnic groups in prostate cancer clinical trials involving germline testing.

\begin{tabular}{|c|c|c|c|c|c|c|c|c|}
\hline \multirow[t]{2}{*}{ Trial } & \multicolumn{5}{|l|}{ Race } & \multicolumn{3}{|c|}{ Ethnicity (Hispanic or Latino) } \\
\hline & $N$ & White & Black & Asian & Other/Unknown & No & Yes & Unknown \\
\hline \multicolumn{9}{|l|}{ Metastatic Hormone Sensitive Prostate Cancer } \\
\hline CHAARTED—Docetaxel [72] & 790 & 674 & 76 & NR & 40 & NR & NR & NR \\
\hline STAMPEDE-Docetaxel [73] & 2962 & NR & NR & NR & NR & NR & NR & NR \\
\hline LATITUDE_Abiraterone [74] & 1199 & NR & NR & NR & NR & NR & NR & NR \\
\hline STAMPEDE-Abiraterone [75] & 1917 & NR & NR & NR & NR & NR & NR & NR \\
\hline ARCHES_Enzalutamide [77] & 1150 & 926 & 16 & 155 & 53 & NR & NR & NR \\
\hline ENZAMET_Enzalutamide [78] & 1125 & NR & NR & NR & NR & NR & NR & NR \\
\hline \multicolumn{9}{|l|}{ MCRPC } \\
\hline TAX 327-Docetaxel [79] & 1006 & NR & NR & NR & NR & NR & NR & NR \\
\hline TROPIC—Cabazitaxel [80] & 755 & 631 & 40 & 58 & 26 & NR & NR & NR \\
\hline AFFIRM—Enzalutamide post-chemo [85] & 1199 & NR & NR & NR & NR & NR & NR & NR \\
\hline PREVAIL_Enzalutamide pre-chemo [86] & 1717 & 1324 & 34 & 167 & 192 & 1527 & 38 & 152 \\
\hline \multicolumn{9}{|l|}{ NMCRPC } \\
\hline SPARTAN_Apalutamide [87] & 1200 & 800 & 68 & 140 & 192 & NR & NR & NR \\
\hline PROSPER_Enzalutamide [88] & 1401 & NR & NR & NR & NR & NR & NR & NR \\
\hline ARAMIS-Darolutamide [89] & 1509 & NR & NR & NR & NR & NR & NR & NR \\
\hline
\end{tabular}

MCRPC metastatic castration-resistant prostate cancer, NMCRPC non-metastatic castration-resistant prostate cancer, NR not reported.

other Hispanic subgroups [10]. Ultimately, the dearth of PCa studies examining individual Hispanic subgroups makes it difficult to compare them to NHW men.

Despite these documented disparities, African-American/ Canadian, Asian/Pacific Islander, and Hispanic populations are typically underrepresented in germline testing, clinical trials (Table 1), and study cohorts [13]. One study analyzed 72 global phase III and IV prevention, screening, and treatment PCa clinical trials between 1987 and 2016: 59 trials reported race/ ethnicity data, and $96 \%$ of patients enrolled in these studies were NHW men. African and Caribbean medical centers were particularly underrepresented in these trials [14]. Concordant studies have shown that the majority of PCa patients receiving germline testing are NHW men $[15,16]$, with as high as $95 \%$ being English-speaking men [16]. Underrepresentation of racial/ethnic minorities in germline testing is not unique to $\mathrm{PCa}$ and exists among patients with various other malignancies [17-19].

Racial/ethnic minority populations in the US are expected to grow rapidly over the coming decades, underscoring the need to address and resolve these disparities. It is projected that by 2045 , NHW people will make up $<50 \%$ of the total US population. While NHW populations are expected to decline, all other racial/ethnic minority populations are expected to grow: in particular, Hispanic populations are the fastest growing demographic and are expected to comprise $24.6 \%$ of the US population in 2045, up from $18.7 \%$ in 2020 [20].

\section{GENOMICS OF NON-WHITE MEN WITH PCA}

$\mathrm{P} / \mathrm{LPV}$ s have been found to be prevalent in men with $\mathrm{PCa}$. A 2016 multi-institutional study found that the incidence of germline mutations in genes mediating DNA-repair processes (including but not limited to BRCA2, ATM, CHEK2, BRCA1,
RAD51D, and PALB2) among 692 men with metastatic PCa was $11.8 \%$ [3]. For patients with localized disease, the prevalence of P/LPVs ranged from 2 to $6 \%$, with increased prevalence in men with higher Gleason scores and higher-risk PCa. Notably, 576 $(83 \%)$ of the men in this study were NHW men. Additionally, a 2021 study found that $9.5 \%$ of PCa patients with high-risk localized disease had P/LPVs, most frequently in BRCA2 and ATM [21].

In order to better understand the genomic landscape of racial/ ethnic minorities, there is a need to more extensively examine P/ LPV rates in non-white men with PCa. More recent studies have found that the prevalence of P/LPVs varies across racial/ethnic groups. When compared to NHW men, Hispanic men with PCa have been found to have similar rates of P/LPVs in the ATM, BRCA1, and $B R C A 2$ genes [22], while Black men with PCa have been found more likely to have a P/LPV in the BRCA1 gene than their NHW counterparts [23]. Among patients with metastatic $\mathrm{PCa}$, mutations in DNA-repair genes have been found to occur more often in Black men than in NHW men [24]. However, these studies were limited by small sample size.

The lack of diversity in germline testing cohorts is thought to be a contributor to higher rates of variants of uncertain significance (VUS) in racial/ethnic minorities $[15,25]$. Notably, African-American, Hispanic, and Asian/Pacific Islander PCa patients have been found to be more likely to have a VUS than those with European ancestry $[23,26]$. In one study of PCa patients referred to Color Genomics for germline testing, VUS rates in HBOC and Lynch syndrome genes were $21 \%$ in NHW men, while $26.6 \%$ and $33.3 \%$ in African-American/Canadian and Asian/Pacific Islander men, respectively [15]. Increasing the proportion of underrepresented groups in germline testing cohorts is predicted to result in the reclassification of VUS, which will assist in cancer risk stratification and targeted therapy strategies [15]. 
Table 2. Guidelines on germline testing in prostate cancer.

\begin{tabular}{lll}
\hline Source & $\begin{array}{l}\text { Regional (N1)/ } \\
\text { metastatic } \\
\text { prostate cancer }\end{array}$ & $\begin{array}{l}\text { NCCN very high } \\
\text { prostate cance }\end{array}$ \\
\hline $\begin{array}{l}\text { National Comprehensive } \\
\text { Cancer Network Version }\end{array}$ & Recommend & Recommend \\
$1.2022[27,28]$ & & \\
\hline
\end{tabular}

$1.2022[27,28]$

Philadelphia Prostate Cancer Consensus Meeting

Publication 2019 [90]
Recommend

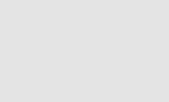

\author{
AUA/ASTRO/SUO 2017 and \\ 2021 [91-93]
}

Recommend
- Consider for T3a or higher.

- Consider for intraductal/ductal pathology.

- Consider for Gleason 4 (Gleason 8 sum) or above.

- Consider for Ashkenazi Jewish ancestry.

- Consider for family history of two or more cancers in HBOC/Lynch spectrum in any relatives on the same side of the family (especially if diagnosed at age $<50$ years).

- Recommend for family history of one brother/father/two or more male relatives with one of the following:

- PCa at age $<60$ years

- Died of PCa.

- Metastatic PCa.

Recommend if a strong family history of Not recommended specific cancers (e.g., breast, ovarian, pancreatic, other gastrointestinal tumors, and lymphoma).

PCa Prostate Cancer, HBOC Hereditary Breast and Ovarian Cancer Syndrome, NCCN National Comprehensive Network, AUA American Urological Association, ASTRO American Society of Radiation Oncology, SUO Society of Urologic Oncology, GG Grade Group.

\section{INDICATIONS FOR GERMLINE TESTING AND IMPLICATIONS OF TESTING RESULTS}

Recent studies on the incidence of P/LPVs among men with PCa have resulted in updated guidance regarding which patients should receive germline testing. The most recent iteration of the National Comprehensive Cancer Network guidelines for PCa recommends germline testing for all men with high-risk localized and metastatic PCa, Ashkenazi Jewish ancestry, a family history of high-risk germline mutations, or a positive family history of cancer [27, 28]. Given emerging data on the association between intraductal/cribriform and ductal histologies and P/LPVs, testing is considered for men with these histologic subtypes [28]. Other professional societies and expert panels have also provided recommendations for germline testing for men with PCa, largely based on evidence synthesis, consensus agreement, and expert opinion (Table 2).

Expanding germline testing uptake may help clinicians predict outcomes in men with PCa by detecting ethnicity-dependent biomarkers and mutations that drive aggressive tumor biology [29]. Germline mutations in DNA-repair genes, particularly $B R C A 1 / 2$ and $A T M$, are associated with aggressive PCa and significantly shorter survival time: mutation carriers have been found to have a higher proportion of Gleason Score $\geq 7$ (71\%) than noncarriers (31\%) and mutation frequency has been found to be significantly higher in patients that have died of PCa than in localized PCa patients [30].

Germline testing also has implications regarding candidacy of select treatments, including platinum chemotherapy, poly(ADPribose) polymerase (PARP) inhibitors, and checkpoint inhibition for patients with metastatic castration-resistant prostate cancer
(mCRPC) [31]. In 2020, the PARP inhibitor Olaparib was FDA approved for the treatment of adult patients with deleterious/ suspected deleterious germline or somatic homologous recombination repair (HRR) gene-mutated $\mathrm{mCRPC}$ who have progressed following prior treatment with enzalutamide or abiraterone. Olaparib is FDA approved for a panel of 14 genes, including $B R C A 1 / 2$. Of the patients in the PROfound trial, $69 \%$ were white, $29 \%$ were Asian, and $1 \%$ were Black [32]. Another therapy, Rucaparib, was FDA approved in 2020 for the treatment of adult patients with a deleterious BRCA1/2 mutation (germline and/or somatic)-associated $\mathrm{mCRPC}$ who have been treated with androgen receptor-directed therapy and a taxane-based chemotherapy. For the 115 patients enrolled in the TRITON2 study, the majority were white $(73 \%)$ and $10 \%$ were Black; other racial/ethnic groups were not specified [33]. Pembrolizumab has also been FDA approved for patients with refractory metastatic cancers with MSIhigh or MMR deficiency (dMMR) status based on tumor assessment that had progressed following prior treatments [34]. Pembrolizumab has shown antitumor activity with an acceptable safety profile in an unselected subset of patients with mCRPC [35].

Another indication for germline testing is cascade testing, which refers to germline testing among relatives of patients with cancer-associated P/LPVs; it has historically had decreased uptake in the community at around $30 \%$ or less. Being a PCa patient with a germline P/LPV in a DNA-repair gene has been associated with having a first degree relative with breast or ovarian cancer [36]. Therefore, increased germline testing among PCa patients may result in increased cascade testing for family members and subsequent breast and ovarian cancer risk mitigation. 
Table 3. Challenges and solutions.

\begin{tabular}{|c|c|}
\hline Challenges & Solutions \\
\hline Shortage of CGCs and limitations of current GC models & $\begin{array}{l}\text { - Increase clinical training capacity for CGCs } \\
\text { - Offer pretest GC and select posttest GC via alternative methods (telemedicine, } \\
\text { group GC) } \\
\text { - Automate risk assessment }\end{array}$ \\
\hline Differences in the quality of care for minority patients & $\begin{array}{l}\text { - Increase access to genetic services, contain costs, and address provider implicit } \\
\text { bias }\end{array}$ \\
\hline Medical mistrust & $\begin{array}{l}\text { - System wide interventions to address gaps in healthcare delivery } \\
\text { - Increase representation of minorities in healthcare } \\
\text { - Community outreach }\end{array}$ \\
\hline Lack of knowledge regarding testing & $\begin{array}{l}\text { - Increase genetics education among patients and community health providers } \\
\text { - Culturally tailored genetic counseling }\end{array}$ \\
\hline $\begin{array}{l}\text { Prohibitive cost and lack of insurance coverage for germline } \\
\text { testing }\end{array}$ & $\begin{array}{l}\text { - Increase payer coverage } \\
\text { - Low-cost testing and government subsidies }\end{array}$ \\
\hline Understudied link between PCa and breast/ovarian cancers & $\begin{array}{l}\text { - Address similar disparities in germline testing among women with } \mathrm{HBOC} \\
\text { syndrome } \\
\text { - Physician and patient directed education regarding genetic link between PCa and } \\
\text { HBOC syndrome }\end{array}$ \\
\hline
\end{tabular}

CGC Clinical Genetic Counselor, GC Genetic Counseling, PCa Prostate Cancer, HBOC syndrome Hereditary Breast and Ovarian Cancer Syndrome.

\section{REASONS FOR THE DISPARITIES IN GERMLINE TESTING AMONG RACIAL/ETHNIC MINORITIES WITH PCA AND POTENTIAL STRATEGIES TO BRIDGE THE GAP}

Although germline testing is now routinely recommended for high-risk localized, locally advanced, and metastatic PCa patients, there is a disparity in the proportion of white vs. non-white PCa patients receiving germline testing $[15,16,26]$. We propose several reasons and potential solutions for this disparity, including the (1) nationwide shortage of genetic counselors to facilitate germline testing within current genetic counseling models, (2) differences in access to quality healthcare between white and non-white patients, (3) healthcare system mistrust among nonwhite men leading to unfavorable attitudes towards research and reluctance to seek care, (4) lack of knowledge or education about germline testing, (5) prohibitive cost of germline testing, and (6) understudied link between PCa and breast/ovarian cancer (Table 3).

\section{Challenge and solution: shortage of genetic counselors and limitations of current genetic counseling models}

Certified Genetic Counselors (CGCs) and physicians work cooperatively to facilitate germline testing and provide counseling, risk assessment, and result interpretation to PCa patients. The shortage of clinical cancer CGCs engaged in direct patient care creates an unmet need for genetic services that disproportionately affects socioeconomically disadvantaged, rural, and racial/ethnic minority patients. As the demand for germline testing grows, CGC workforce growth limitations will need to be addressed. One such limitation is clinical training capacity. Proposed solutions include novel clinical training techniques, such as nonclinical or extra-disciplinary training placements, rural clinical placements, peer supervision/assisted learning, role-emerging placements, clinical audit, and patient simulation. Perhaps most important is the need to recruit, train, and retain clinical supervisors by providing dedicated support personnel and professional development opportunities [37].

In addition to a nationwide shortage of CGCs engaged in direct patient care, existing genetic counseling models are becoming increasingly inadequate given the number of PCa patients referred for germline testing. The current time-intensive model of assessing family histories for genetic risk, providing pretest and posttest counseling, ordering appropriate testing, and interpreting test results over multiple in-person sessions is increasingly less feasible. Increased genetic literacy among medical oncologists, urologists, and radiation oncologists, including knowledge of patient risk factors and family history, genetics and genetic conditions, and available genetic services, may alleviate bottlenecks at the genetic counseling level [38].

Modifications to existing workflows within oncology practices may expand genetic resources for patients. Automating the risk assessment would be one such modification, whereby patientcompleted family history questionnaires facilitate referral and testing processes: automated electronic medical record features can trigger genetic counseling referrals or alert clinical teams to patients with elevated cancer risks or who meet guidelines for germline testing. This would allow CGCs to prioritize posttest visits, especially those involving complex counseling or abnormal results [39]. Other practical strategies focus on increasing CGC efficiency and patient volumes, including group genetic counseling sessions. Additionally, establishing support roles, such as genetic counseling assistants, can alleviate administrative burdens [8]. Likewise, patient advocates and language interpreters in the genetic counseling setting can provide resources and translation services for non-English-speaking patients, which would further alleviate burdens on monolingual English-speaking CGCs and reduce patient miscommunication.

Rural patients are particularly disadvantaged by current genetic counseling models, given the scarcity of CGCs in more rural counties and among populations with a low median household income [40]. Telemedicine, which has been adopted by many clinics in the COVID-19 era [41], can help bridge this gap: video genetics education and genetic counseling may be as effective as traditional genetic counseling and has resulted in a similar uptake of germline testing without compromising the tenants of informed consent [42]. Telemedicine models do, however, need to adapt to potential challenges, including limited internet access, scheduling issues, billing questions, and state licensure regulations [41].

\section{Challenge and solution: differences in the quality of care between white and non-white patients}

There is overwhelming evidence that there are disparities in the quality of healthcare between white and non-white patients, even when insurance status, income, age, and severity of conditions are comparable [43]. Significant disparities have been noted for definitive therapy for $\mathrm{PCa}$ [6], with Black men being particularly underrepresented in PCa research, including validation studies of new clinical tools like genomic testing $[15,44]$. One explanation 


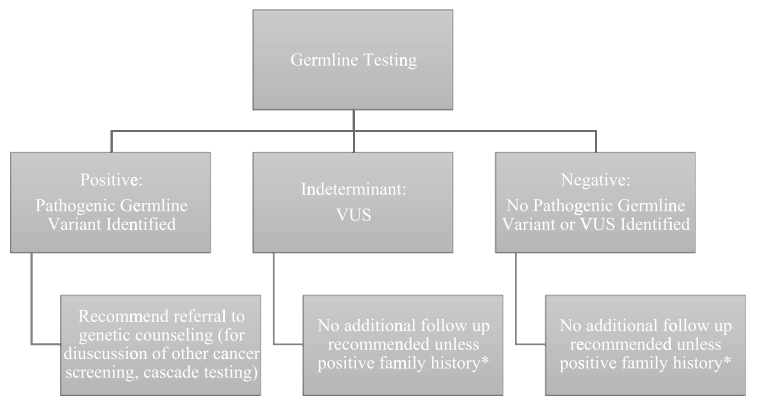

VUS=Variant of uncertain significance

Fig. 1 Post-germline testing workflow depending on test result $[27,28]$. VUS Variant of uncertain significance. ${ }^{*}$ Genetic counseling recommended to discuss possible participation in family studies and variant reclassification studies.

for this disparity is that minority-serving physicians have been found to be significantly less likely to have ever referred a patient for germline testing or counseling, specialty services, or clinical trials [45]. This may be the result of many underlying issues, including access and cost.

Strategies to integrate genetic services into minority community health settings will be critical in ensuring the accessibility of germline testing. Because most CGCs are concentrated within large academic medical centers and hospital systems, the incorporation of satellite campuses and clinics into medically underserved communities would greatly expand access. In tandem, minority community health programs can practice evidence based medicine through the implementation of clinical pathways to ensure that all patients are receiving the minimum standard of care. This will require expanding physician knowledge and awareness of current PCa clinical practice guidelines, as well as integration of these guidelines into existing workflows (Fig. 1).

Despite the expansion of germline testing guidelines for $\mathrm{PCa}$ patients, germline testing is not routinely covered by insurance. Coverage policies for germline testing in PCa patients are nonspecific and nonuniform across insurance companies, and physicians may not recommend genetic services for patients who cannot afford the out-of-pocket costs [46]. Expanding insurance coverage to include PCa patients that meet recommendations for germline testing may alleviate cost barriers. Additionally, in the absence of genetic services in medically underserved communities, expanded insurance coverage for transportation costs may benefit those who cannot access such services due to geographic barriers and for whom in-person counseling may help overcome hesitation due to unfamiliarity with telemedicine and/or lack of trust in the healthcare system.

\section{Challenge and solution: medical mistrust leading to unfavorable attitudes towards research and medicine}

Healthcare disparities among racial/ethnic minorities are thought to contribute to long-standing generational mistrust in healthcareproviding entities in the US. Medical mistrust has been shown to lower utilization of routine checkups and preventive care services [47-49], including referrals for genetic counseling and testing. Delays in these services may prevent a substantial number of men from obtaining recommended services until an advanced stage of illness [47]. This mistrust becomes a barrier to an emphasis on prostate health [50] and precludes racial/ethnic minorities from seeking PCa screening, germline testing, and treatment.

The lack of representation within medical institutions, as well as subsequent language barriers, may be a contributor to medical mistrust. In 2019, 5.0\% and 5.8\% of physicians identified as Black and Hispanic, respectively [51]. Further, $10.0 \%$ of CGCs in the US identified as non-white in 2021 [52]. Representation improves patient-clinician communication and rapport: when provided a doctor of the same race, Black men have been found be more likely consent to invasive services, such as blood draws and biopsies, and discuss personal matters or health issues [53]. Hispanic men, in contrast, may face language barriers with clinicians: monolingual English-speaking clinicians may have limited communication with patients or rely on interpreters or translated materials, which may convey confusing or even contradictory information [54]. Issues of representation can be addressed by actively recruiting racial/ethnic minorities to the healthcare workforce and creating student training programs targeting these populations [55]. Language challenges can be addressed by employing multilingual, culturally cognizant interpreters in clinics where the need exists [56].

Medical mistrust may also stem from implicit bias, which refers to the unconscious and unintentional attitudes and stereotypes attributed towards a group of people. Implicit bias may contribute to health disparities by shaping physician behavior and producing differences in treatment along the lines of race, ethnicity, and gender. Healthcare professionals can combat implicit bias by individuating, which involves a conscious focus on specific information about a patient instead of their race, ethnicity, or gender [57]. Addressing implicit bias early is essential: genetic counseling and nursing programs, medical schools, and healthcare professional training programs can expand and emphasize coursework in racial sensitivity and implicit bias. Additionally, addressing implicit bias in continuing medical education may help minimize biases.

Medical mistrust may also result from a lack of trust regarding the use of genetic information. Despite the passage of the Genetic Information Nondiscrimination Act in 2008, which was designed to protect Americans against discrimination in health insurance and employment based on their genetic information [58], utilization of genetic services among racial/ethnic minorities is disproportionately low [59]. In response, providers need to anticipate and dispel patient fears about germline testing. Patients may believe that their results are not confidential or that positive results will leave them susceptible to discrimination, reduced access to care, or insurance coverage loss [44]. Patients may also conflate germline testing ordered by a clinician with direct-to-consumer DNA testing provided by companies that have faced controversy for sharing customers' data with law enforcement and pharmaceutical companies.

Outreach and community support may help combat medical mistrust. Distributing medical literature directly to underserved populations has been shown to have positive results; however, personalized interactions between clinicians and racial/ethnic minority communities may further build trust and assuage fears about genetic services in order to encourage participation in germline testing and clinical trials [59]. Outreach and educational efforts within community institutions (such as churches) that involve partners and spouses, as well as cancer survivors within the community, may play a pivotal role [60].

Challenge and solution: lack of knowledge regarding testing A lack of knowledge regarding germline testing and its implications for PCa screening, diagnostics, and treatment may present further barriers [38]. The availability of reliable, easy-to-understand information regarding the effects of P/LPVs on disease, as well as the importance of personal or family history of disease, is crucial [56].

Access to clear, concise tools about genetics is important because the complexity of such tools may compromise their effectiveness in identifying individuals at-risk for PCa. Genetics education among the general public is also important because individuals who are aware of and ask for specialized genetic services are the most likely to receive them [25]. Clear, simple, prescriptive education on genetics needs to be widely available to all PCa patients, and physicians will need to communicate the 
408

advantages of genetic counseling and germline testing when they encounter high-risk localized and metastatic PCa patients who may benefit from it [40].

A lack of cross-cultural communication may also prevent racial/ ethnic minorities from seeking or consenting to germline testing. The cultural impact of cancer can have an effect on patients' attitudes towards germline testing: some South Asian and AfricanAmerican communities have been found to take on a fatalistic view of cancer, associating the diagnosis with death; they may not wish to pursue testing if they believe nothing can be done to prevent or treat it [61]. Culture can also have an effect on the acceptance of test results: patients who receive germline testing may fear that their results will ostracize them from their family or community. Additionally, patients may not understand what a positive, negative, or inconclusive result means in the context of their own health and their family's health. One solution could be culturally tailored genetic counseling (CTGC) and testing programs, which have been developed and evaluated to improve access to risk assessment services, subsequently enhancing the quality of care among patients from racial/ethnic minority groups. CTGC consists of education about risk factors for hereditary disease, personalized risk information, and discussions about the benefits, limitations, and risks of germline testing [56].

\section{Challenge and Solution: prohibitive cost and lack of insurance coverage for germline testing}

Access to germline testing is often limited by access to quality, affordable health insurance, which varies by race/ethnicity: NHW people are more likely to have health insurance than racial/ethnic minorities [62]. Additionally, NHW people are more likely to have private health coverage as opposed to public health coverage, such as Medicare and Medicaid [62]. Patients who are uninsured, underinsured, or insured by government programs may face significant barriers to obtaining care-for example, they may be denied care by private physicians, leading them to seek care in emergency departments, public hospital systems, or local health departments which may not offer the same referrals or specialty and preventative services as private practices [63]. Overall, having health insurance is strongly associated with undergoing PCa screening, lower stage of cancer at diagnosis, treatment for local/ regional disease, prostatectomy, PCa survival, and quality of life [5]. Without health insurance, the cost of germline testing is often prohibitive. And, even when germline testing is covered by insurance, there may be prohibitive out-of-pocket costs, including deductibles and copayments. Additionally, not all insurers cover germline testing for $\mathrm{PCa}$ [46], including some private insurers and public options such as Medicare and Medicaid [64].

There are programs that increase PCa patient access to genetic services by offering free or reduced cost germline testing. Color Genomics offers a relatively low-cost risk analysis of several genes associated with PCa, as well as access to CGC and physician services [65]. Additionally, Invitae offers free germline testing and counseling for hereditary PCa through their Detect Hereditary Prostate Cancer program, in which eligible patients work with a genetic counselor or physician to order testing [66]. These, along with research studies such as the patient-driven PROMISE registry, which offers medical Color Genomics germline testing by mail to men with any stage of PCa [67], can reduce cost and access barriers.

Additional strategies for increasing payer coverage for germline testing and reducing test costs are necessary in order to create equitable access for all PCa patients. Strategies to increase insurance coverage may include clarifying and expanding Current Procedural Terminology codes to allow coverage for more specific tests and adding genetic specialists to insurance company staff to address shortages of genetic expertise. To address the costs of genetic tests, government subsidy programs and cost caps may be helpful in mitigating the cost to both the patient and insurers.
Ultimately, there is a need for healthcare coverage reform in the US. In the absence of publicly funded healthcare, improving provider discussions about out-of-pocket costs is critical for ensuring informed patient testing and treatment decisions [64].

\section{Challenge and solution: understudied link between PCa and breast/ovarian cancers}

P/LPVs of BRCA1/2 have been found to increase the risk of multiple cancers, including those of the breast, ovary, and prostate. These $\mathrm{P} / \mathrm{LPV}$ s have clinical implications for PCa patients as well as their families. BRCA1/2 associated HBOC should be suspected in individuals with family history of PCa and other cancers associated with $\mathrm{HBOC}$ syndrome [68], and likewise, PCa risk should be considered in individuals with a personal history of male breast cancer and/or family history suggestive of HBOC syndrome [69].

As with $\mathrm{PCa}$, there are disparities in germline testing rates among racial/ethnic minority women with $\mathrm{HBOC}$ syndrome. These disparities are thought to be a result of multiple factors, including medical mistrust and fears of discrimination on the basis of genetic information [70]. Such disparities are thought to contribute to concordant disparities among racial/ethnic minority men with PCa. Therefore, addressing germline testing disparities among women with $\mathrm{HBOC}$ syndrome may aid in identifying male family members at-risk for developing $\mathrm{PCa}$, as well as those already diagnosed with PCa who would benefit from germline testing's impact on treatment options.

One particular challenge for PCa patients is that the names of certain PCa predisposition genes and familial risk factors (e.g., $B R C A 1 / 2$ and $\mathrm{HBOC}$ syndrome) do not make obvious their link to $\mathrm{PCa}$. As a result, it may not be clear to PCa patients that hereditary mutations in these genes affect them, as their names only indicate a link to breast and ovarian cancers. To address this misconception, one proposal is to change the name of HBOC syndrome to remove the sex specificity of the name [71], which may reduce confusion about its relevance to men.

\section{CONCLUSION}

It is widely accepted that a subset of PCa susceptibility is attributed to inherited predisposition. Because the identification of alterations in PCa predisposition genes may help inform screening strategies for patients and family members, treatment options in the metastatic setting, and clinical trial enrollment, it will become increasingly important to bridge the gap for $\mathrm{PCa}$ patients who are underserved with regard to germline testing. Issues to be addressed include a shortage of genetics professionals, disparities in care, medical mistrust, misinformation, and misunderstanding regarding germline testing, costs, and the understudied link between PCa and breast/ovarian cancer.

\section{REFERENCES}

1. American Cancer Society. Prostate Cancer. 2020. https://www.cancer.org/cancer/ prostate-cancer.html.

2. Siegel RL, Miller KD, Fuchs HE, Jemal A. Cancer statistics, 2021. CA Cancer J Clin. 2021;71:7-33.

3. Pritchard CC, Mateo J, Walsh MF, De Sarkar N, Abida W, Beltran H, et al. Inherited DNA-repair gene mutations in men with metastatic prostate cancer. $\mathrm{N}$ Engl J Med. 2016;375:443-53.

4. Chornokur G, Dalton K, Borysova ME, Kumar NB. Disparities at presentation, diagnosis, treatment, and survival in African American men, affected by prostate cancer. Prostate. 2011;71:985-97.

5. Gilligan T. Social disparities and prostate cancer: mapping the gaps in our knowledge. Cancer Causes Control. 2005;16:45-53.

6. Gross CP, Smith BD, Wolf E, Andersen M. Racial disparities in cancer therapy: did the gap narrow between 1992 and 2002? Cancer. 2008;112:900-8.

7. Richert-Boe KE, Weinmann S, Shapiro JA, Rybicki BA, Enger SM, Van Den Eeden SK, et al. Racial differences in treatment of early-stage prostate cancer. Urology. 2008;71:1172-6. 
8. Krimphove MJ, Cole AP, Fletcher SA, Harmouch SS, Berg S, Lipsitz SR, et al. Evaluation of the contribution of demographics, access to health care, treatment, and tumor characteristics to racial differences in survival of advanced prostate cancer. Prostate Cancer Prostatic Dis. 2019;22:125-36.

9. Odedina FT, Akinremi TO, Chinegwundoh F, Roberts R, Yu D, Reams RR, et al. Prostate cancer disparities in Black men of African descent: a comparative literature review of prostate cancer burden among Black men in the United States, Caribbean, United Kingdom, and West Africa. Infect Agent Cancer. 2009;4 Suppl 1:S2.

10. Chinea FM, Patel VN, Kwon D, Lamichhane N, Lopez C, Punnen S, et al. Ethnic heterogeneity and prostate cancer mortality in Hispanic/Latino men: a population-based study. Oncotarget. 2017;8:69709-21.

11. Dobbs RW, Malhotra NR, Abern MR, Moreira DM. Prostate cancer disparities in Hispanics by country of origin: a nationwide population-based analysis. Prostate Cancer Prostatic Dis. 2019;22:159-67.

12. Katz JE, Chinea FM, Patel VN, Balise RR, Venkatramani V, Gonzalgo ML, et al. Disparities in Hispanic/Latino and non-Hispanic Black men with low-risk prostate cancer and eligible for active surveillance: a population-based study. Prostate Cancer Prostatic Dis. 2018;21:533-8.

13. Nicolosi P, Ledet E, Yang S, Michalski S, Freschi B, O'Leary E, et al. Prevalence of germline variants in prostate cancer and implications for current genetic testing guidelines. JAMA Oncol. 2019;5:523-8.

14. Rencsok EM, Bazzi LA, McKay RR, Huang FW, Friedant A, Vinson J, et al. Diversity of enrollment in prostate cancer clinical trials: current status and future directions. Cancer Epidemiol Biomark Prev. 2020;29:1374-80.

15. Kwon DH, Borno HT, Cheng HH, Zhou AY, Small EJ. Ethnic disparities among men with prostate cancer undergoing germline testing. Urol Oncol. 2020;38:80.e1-7.

16. Borno HT, Odisho AY, Gunn CM, Pankowska M, Rider JR. Disparities in precision medicine-examining germline genetic counseling and testing patterns among men with prostate cancer. Urol Oncol. 2021;39:233.e9-14.

17. Dharwadkar P, Greenan G, Stoffel EM, Burstein E, Pirzadeh-Miller S, Lahiri S, et al. Racial and ethnic disparities in germline genetic testing of patients with youngonset colorectal cancer. Clin Gastroenterol Hepatol. 2020;S1542-3565:31721-3.

18. Yip CH, Evans DG, Agarwal G, Buccimazza I, Kwong A, Morant R, et al. Global disparities in breast cancer genetics testing, counselling and management. World J Surg. 2019;43:1264-70.

19. Parikh DA, Dickerson JC, Kurian AW. Health disparities in germline genetic testing for cancer susceptibility. Cur Breast Cancer Rep. 2020;12:51-8.

20. Bureau UC. Table 4. Projected race and Hispanic origin 2017. 2021. https://www. census.gov/data/tables/2017/demo/popproj/2017-summary-tables.html.

21. Berchuck JE, Zhang Z, Silver R, Kwak L, Xie W, Lee GM, et al. Impact of pathogenic germline DNA damage repair alterations on response to intense neoadjuvant androgen deprivation therapy in high-risk localized prostate cancer. Eur Urol. 2021;S0302-2838:00237-2.

22. Shaya JNS, Hatchell KE, Esplin ED, Nussbaum L, Weise N, Madlensky L, et al. Germline alterations among Hispanic men with prostate cancer. J Clin Oncol. 2021;39:10534.

23. Ledet EM, Burgess EF, Sokolova AO, Jaeger EB, Hatton W, Moses M, et al. Comparison of germline mutations in African American and Caucasian men with metastatic prostate cancer. Prostate. 2021;81:433-9.

24. Mahal BA, Alshalalfa M, Kensler KH, Chowdhury-Paulino I, Kantoff P, Mucci LA et al. Racial differences in genomic profiling of prostate cancer. $N$ Engl J Med. 2020;383:1083-5.

25. Hall MJ, Olopade Ol. Disparities in genetic testing: thinking outside the BRCA box. J Clin Oncol. 2006;24:2197-203.

26. Ndugga-Kabuye MK, Issaka RB. Inequities in multi-gene hereditary cancer testing: lower diagnostic yield and higher VUS rate in individuals who identify as Hispanic, African or Asian and Pacific Islander as compared to European. Fam Cancer. 2019;18:465-9.

27. Daly MB, Pal T, Buys SS, Dickson P, Domchek SM, Elkhanany A, et al. Genetic/ familial high-risk assessment: breast, ovarian, and pancreatic, version 1.2022, NCCN Clinical Practice Guidelines in Oncology. 2021. https://www.nccn.org/ professionals/physician_gls/pdf/genetics_bop.pdf.

28. Schaeffer E, Srinivas S, Antonarakis ES, Armstrong AJ, Cheng HH, D'Amico AV, et al. Prostate Cancer, Version 1.2022, NCCN Clinical Practice Guidelines in Oncology. 2021. https://www.nccn.org/professionals/physician_gls/pdf/prostate.pdf.

29. Spratt DE, Chan T, Waldron L, Speers C, Feng FY, Ogunwobi OO, et al. Racial/ ethnic disparities in genomic sequencing. JAMA Oncol. 2016;2:1070-4.

30. Na R, Zheng SL, Han M, Yu H, Jiang D, Shah S, et al. Germline mutations in ATM and BRCA1/2 distinguish risk for lethal and indolent prostate cancer and are associated with early age at death. Eur Urol. 2017;71:740-7.

31. Merseburger AS, Waldron N, Ribal MJ, Heidenreich A, Perner S, Fizazi K, et al. Genomic testing in patients with metastatic castration-resistant prostate cancer: a pragmatic guide for clinicians. Eur Urol. 2021;79:519-29.

32. Food and Drug Administration. FDA approves olaparib for HRR gene-mutated metastatic castration-resistant prostate cancer. 2020. https://www.fda.gov/drugs/ resources-information-approved-drugs/fda-approves-olaparib-hrr-gene-mutatedmetastatic-castration-resistant-prostate-cancer.

33. Food and Drug Administration. FDA grants accelerated approval to rucaparib for BRCA-mutated metastatic castration-resistant prostate cancer. 2020. https://www.fda. gov/drugs/resources-information-approved-drugs/fda-grants-accelerated-approvalrucaparib-brca-mutated-metastatic-castration-resistant-prostate.

34. Loeb S, Giri VN. Clinical implications of germline testing in newly diagnosed prostate cancer. Eur Urol Oncol. 2021;4:1-9.

35. Antonarakis ES, Piulats JM, Gross-Goupil M, Goh J, Ojamaa K, Hoimes CJ, et al. Pembrolizumab for treatment-refractory metastatic castration-resistant prostate cancer: multicohort, open-label phase II KEYNOTE-199 study. J Clin Oncol. 2020;38:395-405.

36. Sabol RA, Ledet EM, Jaeger E, Hatton W, Moses M, Lankford A, et al. Family history and pathogenic/likely pathogenic germline variants in prostate cancer patients. Prostate. 2021;81:427-32.

37. Berninger $T$, Nusbaum R, Redlinger-Grosse $K$, Davis $C$, Reiser $C$. A narrative literature review: Growing the workforce through increased fieldwork capacity in genetic counseling training programs. J Genet Couns. 2021;30:574-87.

38. Delikurt T, Williamson GR, Anastasiadou V, Skirton H. A systematic review of factors that act as barriers to patient referral to genetic services. Eur J Hum Genet. 2015;23:739-45.

39. Szymaniak BM, Facchini LA, Giri VN, Antonarakis ES, Beer TM, Carlo MI, et al Practical considerations and challenges for germline genetic testing in patients with prostate cancer: recommendations from the germline genetics working group of the PCCTC. JCO Oncol Pract. 2020;16:811-9.

40. Villegas C, Haga SB. Access to genetic counselors in the southern United States. J Pers Med. 2019;9:1-33.

41. Shur N, Atabaki SM, Kisling MS, Tabarani A, Williams C, Fraser JL, et al. Rapid deployment of a telemedicine care model for genetics and metabolism during COVID-19. Am J Med Genet A 2021;185:68-72.

42. Rana HQSJ, Petrucelli N, Koeller DR, Pirzadeh-Miller S, Reys B, Kipnis L, et al. A randomized controlled trial of video-education or in-person genetic counseling for men with prostate cancer (ProGen). J Clin Oncol. 2020;38:1507.

43. Nelson A. Unequal treatment: confronting racial and ethnic disparities in health care. J Natl Med Assoc. 2002;94:666-8.

44. Rogers CR, Rovito MJ, Hussein M, Obidike OJ, Pratt R, Alexander M, et al. Attitudes toward genomic testing and prostate cancer research among Black men. Am J Prev Med. 2018;0 5 Suppl 1:S103-11.

45. Shields $A E$, Burke W, Levy DE. Differential use of available genetic tests among primary care physicians in the United States: results of a national survey. Genet Med. 2008;10:404-14.

46. Zhen JT, Syed J, Nguyen KA, Leapman MS, Agarwal N, Brierley K, et al. Genetic testing for hereditary prostate cancer: current status and limitations. Cancer. 2018;124:3105-17.

47. Hammond WP, Matthews D, Mohottige D, Agyemang A, Corbie-Smith G. Masculinity, medical mistrust, and preventive health services delays among community-dwelling African-American men. J Gen Intern Med. 2010;25:1300-8.

48. LaVeist TA, Isaac LA, Williams KP. Mistrust of health care organizations is associated with underutilization of health services. Health Serv Res. 2009;44:2093-105.

49. Sarver JH, Cydulka RK, Baker DW. Usual source of care and nonurgent emergency department use. Acad Emerg Med. 2002;9:916-23.

50. Allen JD, Kennedy M, Wilson-Glover A, Gilligan TD. African-American men's perceptions about prostate cancer: implications for designing educational interventions. Soc Sci Med. 2007;64:2189-200.

51. American Academy of Medical Colleges. Diversity in medicine: facts and figures 2019. 2019. https://www.aamc.org/data-reports/workforce/interactive-data/ figure-18-percentage-all-active-physicians-race/ethnicity-2018.

52. National Society of Genetic Counselors. 2021 Professional status survey: executive summary. 2020. https://www.nsgc.org/Portals/0/Executive\%20Summary\% 202021\%20FINAL\%2005-03-21.pdf.

53. Alsan MGO, Graziani GC. Does diversity matter for health? Experimental evidence from Oakland. Am Econ Rev. 2019;109:4071-111.

54. Shaw A, Ahmed M. Translating genetics leaflets into languages other than English: lessons from an assessment of Urdu materials. J Genet Couns. 2004;13:321-42.

55. Bouye $\mathrm{KE}, \mathrm{McCl}$ eary $\mathrm{KJ}$, Williams KB. Increasing diversity in the health professions: reflections on student pipeline programs. J Health Sci Humanit. 2016;6:67-79.

56. Halbert $\mathrm{CH}$, Harrison BW. Genetic counseling among minority populations in the era of precision medicine. Am J Med Genet C Semin Med Genet. 2018;178:68-74.

57. Chapman EN, Kaatz A, Carnes M. Physicians and implicit bias: how doctors may unwittingly perpetuate health care disparities. J Gen Intern Med. 2013;28:1504-10.

58. National Institutes of Health NHGRP. The Genetic Information Nondiscrimination Act of 2008. 2021. https://www.genome.gov/27568492/the-genetic-informationnondiscrimination-act-of-2008. 
59. Saulsberry K, Terry SF. The need to build trust: a perspective on disparities in genetic testing. Genet Test Mol Biomark. 2013;17:647-8.

60. Cackowski FC, Mahal B, Heath El, Carthon B. Evolution of disparities in prostate cancer treatment: is this a new normal? Am Soc Clin Oncol Educ Book. 2021;41:1-12.

61. Allford A, Qureshi N, Barwell J, Lewis C, Kai J. What hinders minority ethnic access to cancer genetics services and what may help? Eur J Hum Genet. 2014;22:866-74.

62. Keisler-Starkey KBL Health Insurance Coverage in the United States: 2019 Current Population Reports: US Department of Commerce, US Census Bureau. 2020. https://www.census.gov/content/dam/Census/library/publications/2020/demo/ p60-271.pdf.

63. Ward E, Halpern M, Schrag N, Cokkinides V, DeSantis C, Bandi P, et al. Association of insurance with cancer care utilization and outcomes. CA Cancer J Clin. 2008:58:9-31.

64. Yabroff KR, Zhao J, de Moor JS, Sineshaw HM, Freedman AN, Zheng Z, et al. Factors associated with oncologist discussions of the costs of genomic testing and related treatments. J Natl Cancer Inst. 2020;112:498-506.

65. Color Genomics. Products. 2021. https://www.color.com/providers/products.

66. Invitae. Detect Hereditary Prostate Cancer. 2021. https://www.invitae.com/en/ detect-hereditary-prostate-cancer/.

67. Promise. 2021. https://www.prostatecancerpromise.org/.

68. Petrucelli N, Daly MB, Pal T. BRCA1- and BRCA2-associated hereditary breast and ovarian cancer. GeneReviews. 1998:1993-2021.

69. Giri VN, Hegarty SE, Hyatt C, O'Leary E, Garcia J, Knudsen KE, et al. Germline genetic testing for inherited prostate cancer in practice: implications for genetic testing, precision therapy, and cascade testing. Prostate. 2019;79:333-9.

70. Armstrong K, Micco E, Carney A, Stopfer J, Putt M. Racial differences in the use of BRCA $1 / 2$ testing among women with a family history of breast or ovarian cancer. JAMA. 2005;293:1729-36.

71. Pritchard CC. New name for breast-cancer syndrome could help to save lives. Nature. 2019;571:27-9.

72. Sweeney CJ, Chen YH, Carducci M, Liu G, Jarrard DF, Eisenberger M, et al. Chemohormonal therapy in metastatic hormone-sensitive prostate cancer. $\mathrm{N}$ Engl J Med. 2015;373:737-46.

73. James ND, Sydes MR, Clarke NW, Mason MD, Dearnaley DP, Spears MR, et al. Addition of docetaxel, zoledronic acid, or both to first-line long-term hormone therapy in prostate cancer (STAMPEDE): survival results from an adaptive, multiarm, multistage, platform randomised controlled trial. Lancet. 2016:387:1163-77.

74. Fizazi K, Tran N, Fein L, Matsubara N, Rodriguez-Antolin A, Alekseev BY, et al. Abiraterone plus prednisone in metastatic, castration-sensitive prostate cancer. $\mathrm{N}$ Engl J Med. 2017;377:352-60.

75. James ND, de Bono JS, Spears MR, Clarke NW, Mason MD, Dearnaley DP, et al. Abiraterone for prostate cancer not previously treated with hormone therapy. $\mathrm{N}$ Engl J Med. 2017:377:338-51.

76. Chi KN, Agarwal N, Bjartell A, Chung BH, Pereira de Santana Gomes AJ, Given R, et al. Apalutamide for metastatic, castration-sensitive prostate cancer. $\mathrm{N}$ Engl J Med. 2019;381:13-24.

77. Armstrong AJ, Szmulewitz RZ, Petrylak DP, Holzbeierlein J, Villers A, Azad A. at al. ARCHES: a randomized, phase III study of androgen deprivation therapy with enzalutamide or placebo in men with metastatic hormone-sensitive prostate cancer. J Clin Oncol. 2019 ;37:2974-86.

78. Davis ID, Martin AJ, Stockler MR, Begbie S, Chi KN, Chowdhury S, et al. Enzalutamide with standard first-line therapy in metastatic prostate cancer. N Engl J Med. 2019;381:121-31

79. Tannock IF, de Wit R, Berry WR, Horti J, Pluzanska A, Chi KN, et al. Docetaxel plus prednisone or mitoxantrone plus prednisone for advanced prostate cancer. $\mathrm{N}$ Engl J Med. 2004;351:1502-12.

80. de Bono JS, Oudard S, Ozguroglu M, Hansen S, Machiels JP, Kocak I, et al. Prednisone plus cabazitaxel or mitoxantrone for metastatic castration-resistant prostate cancer progressing after docetaxel treatment: a randomised open-label trial. Lancet. 2010;376:1147-54

81. Kantoff PW, Higano CS, Shore ND, Berger ER, Small EJ, Penson DF, et al. Sipuleucel-T immunotherapy for castration-resistant prostate cancer. N Engl J Med. 2010;363:411-22.

82. Parker C, Nilsson S, Heinrich D, Helle SI, O'Sullivan JM, Fosså SD, et al. Alpha emitter radium-223 and survival in metastatic prostate cancer. $\mathrm{N}$ Engl J Med. 2013;369:213-23.
83. de Bono JS, Logothetis CJ, Molina A, Fizazi K, North S, Chu L, et al. Abiraterone and increased survival in metastatic prostate cancer. $\mathrm{N}$ Engl J Med. 2011;364:1995-2005.

84. Ryan CJ, Smith MR, de Bono JS, Molina A, Logothetis CJ, de Souza $P$, et al. Abiraterone in metastatic prostate cancer without previous chemotherapy. $\mathrm{N}$ Engl J Med. 2013;368:138-48.

85. Scher HI, Fizazi K, Saad F, Taplin ME, Sternberg CN, Miller K, et al. Increased survival with enzalutamide in prostate cancer after chemotherapy. $\mathrm{N}$ Engl J Med. 2012;367:1187-97.

86. Beer TM, Armstrong AJ, Rathkopf DE, Loriot $\mathrm{Y}$, Sternberg CN, Higano CS, et al. Enzalutamide in metastatic prostate cancer before chemotherapy. N Engl J Med. 2014;371:424-33.

87. Smith MR, Saad F, Chowdhury S, Oudard S, Hadaschik BA, Graff JN, et al. Apalutamide treatment and metastasis-free survival in prostate cancer. $\mathrm{N}$ Engl J Med. 2018;378:1408-18.

88. Hussain M, Fizazi K, Saad F, Rathenborg P, Shore N, Ferreira U, et al. Enzalutamide in men with nonmetastatic, castration-resistant prostate cancer. N Engl J Med. 2018;378:2465-74

89. Fizazi K, Shore N, Tammela TL, Ulys A, Vjaters E, Polyakov S, et al. Darolutamide in nonmetastatic, castration-resistant prostate cancer. $N$ Engl J Med. 2019;380:1235-46.

90. Giri VN, Knudsen KE, Kelly WK, Cheng HH, Cooney KA, Cookson MS, et al. Implementation of germline testing for prostate cancer: Philadelphia Prostate Cancer Consensus Conference 2019. J Clin Oncol. 2020;38:2798-811.

91. Lowrance WT, Breau RH, Chou R, Chapin BF, Crispino T, Dreicer R, et al. Advanced prostate cancer: AUA/ASTRO/SUO Guideline PART I. J Urol. 2021;205:14-21.

92. Lowrance WT, Breau RH, Chou R, Chapin BF, Crispino T, Dreicer R, et al. Advanced prostate cancer: AUA/ASTRO/SUO Guideline PART II. J Urol. 2021;205:22-9.

93. Sanda MG, Chen RC, Crispino T, Freedland S, Greene K, Klotz LH, et al. Clinically localized prostate cancer: AUA/ASTRO/SUO Guideline: American Urological Association. 2017. https://www.auanet.org/guidelines/guidelines/prostatecancer-clinically-localized-guideline\#x6914.

\section{ACKNOWLEDGEMENTS}

PNW SPORE CA097186; Congressional Designated Medical Research Program (CDMRP) award W81XWH-17-2-0043; P30 CA015704; Prostate Cancer Foundation

\section{AUTHOR CONTRIBUTIONS}

Concept and design: RRM. Acquisition, analysis or interpretation of data: NW, JS. Drafting of paper: NW, RRM. Critical revisions of paper for important intellectual content: NW, JS, JJD, HHC, LM, and RRM. Approval of final paper: NW, JS, JJD, HHC, LM, and RRM. Supervision: RRM.

\section{COMPETING INTERESTS}

$\mathrm{HHC}$ received research funding to her institution from Astellas, Clovis Oncology, Color Foundation, Janssen, Medivation, Phosplatin, and Sanofi; is a consultant for AstraZeneca. RRM received research funding from Bayer, Pfizer, Tempus; serves on Advisory Board for AstraZeneca, Bayer, Bristol Myers Squibb, Calithera, Exelixis, Janssen, Merck, Novartis, Pfizer, Sanofi, Tempus; is a consultant for Dendreon, Myovant, Vividion; serves on the molecular tumor board at Caris. The remaining authors declare no competing interests.

\section{ADDITIONAL INFORMATION}

Correspondence and requests for materials should be addressed to Rana R. McKay.

Reprints and permission information is available at http://www.nature.com/ reprints

Publisher's note Springer Nature remains neutral with regard to jurisdictional claims in published maps and institutional affiliations. 